\title{
The effects of adjuvant endocrine therapy on bone health in women with breast cancer
}

\author{
Sabashini K Ramchand ${ }^{1,2}$, Yee-Ming Cheung ${ }^{1,2}$, Belinda Yeo ${ }^{3,4}$ and Mathis Grossmann ${ }^{1,2}$ \\ 1Department of Endocrinology, Austin Health, Heidelberg, Victoria, Australia \\ 2Department of Medicine, Austin Health, The University of Melbourne, Heidelberg, Victoria, Australia \\ ${ }^{3}$ Department of Oncology, Austin Health, Heidelberg, Victoria, Australia \\ ${ }^{4}$ Olivia Newton-John Cancer Research Institute, Heidelberg, Victoria, Australia
}

Correspondence should be addressed to S K Ramchand: sabashini.ramchand@austin.org.au

\begin{abstract}
In women with oestrogen receptor (ER)-positive early breast cancer, oestradiol is important for breast cancer development and progression. Endocrine therapy prevents the deleterious effects of oestradiol in breast tissue by systemically depleting oestradiol concentration (aromatase inhibitors) or preventing its local action in breast tissue (selective oestrogen receptor modulators i.e. tamoxifen), thereby improving oncological outcomes. Use of aromatase inhibitors in postmenopausal women and ovarian function suppression with either tamoxifen or aromatase inhibition in premenopausal women, consequent to systemic oestradiol depletion, exerts detrimental effects on skeletal health. The oestradiol-deficient state causes increased bone remodelling and a negative bone balance. This results in bone loss, microstructural deterioration and bone fragility predisposing to fractures. Similar effects are also seen with tamoxifen in premenopausal women. In contrast, use of tamoxifen in postmenopausal women appears to exert protective effects on bone but studies on fracture risk are inconclusive. The longevity of women with ER-positive breast cancer treated with adjuvant endocrine therapy emphasises the need to mitigate the adverse skeletal effects of these therapies in order to maximise benefit. In general, fractures are associated with increased morbidity, mortality and are a high socioeconomic burden. Whilst the efficacy of antiresorptive therapy in preventing bone mineral density loss in postmenopausal women has been established, further clinical trial evidence is required to provide guidance regarding fracture risk reduction, when to initiate and stop treatment, choice of agent and optimal management of bone health in premenopausal women receiving endocrine therapy. In addition, potential oncological benefits of antiresorptive therapies will also need to be considered.
\end{abstract}

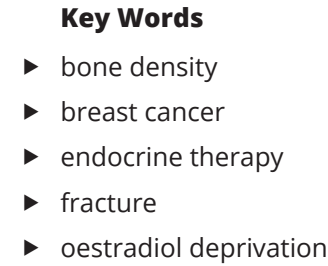

Journal of Endocrinology (2019) 241, R111-R124

\section{Introduction}

Breast cancer is the most common cancer diagnosed in women worldwide, contributing $25.4 \%$ of the total number of new cases diagnosed in 2018 (www.wcrf.org). Due to earlier detection and advances in treatment, the 5 -year survival rate in women with early breast cancer is currently greater than 90\% (Early Breast Cancer Trialists'
Collaborative Group 2015b), emphasising the need to mitigate adverse long-term treatment effects.

Approximately $75 \%$ of diagnosed breast tumours express oestrogen receptors (ERs) and are termed ER-positive breast cancers (Nadji et al. 2005). Oestradiol is important for stimulating breast cancer growth and 
proliferation and treatment with endocrine therapy, which attempts to prevent proliferative oestradiol signalling in breast cancer cells, is routine care. In addition to its effects on breast cancer cells, oestradiol also plays a vital role in a number of physiological mechanisms including the regulation of bone metabolism (Riggs et al. 2002). Adjuvant endocrine therapy significantly reduces the risk of breast cancer recurrence, increasing the likelihood of cure, but due to its systemic effects on oestradiol, it has unintended adverse effects on skeletal health. Concurrent use of gonadotropin-releasing hormone $(\mathrm{GnRH})$ analogues with either tamoxifen or an aromatase inhibitor (AI) in premenopausal women and AIs in postmenopausal women causes accelerated bone loss and increased risk of fracture. Tamoxifen, a selective oestrogen receptor modulator, causes bone loss in premenopausal women but is bone protective in postmenopausal women.

In the general population, fragility fractures adversely affect quality of life, increase morbidity and mortality and are associated with a high socioeconomic burden (Pisani et al. 2016). Therefore, minimisation of bone loss and ultimately fracture prevention is a significant survivorship issue that needs to be addressed. This review will discuss the effects of endocrine therapy on skeletal health in women with ER-positive early breast cancer and outline current evidence regarding pharmacotherapy to prevent bone loss and minimise fracture risk in these women. Material discussed is based on peer reviewed publications indexed on the PubMed database, from 1970 to December 2018, using, in various combinations, the search terms 'aromatase inhibitors', 'bisphosphonates', 'bone health', 'denosumab', 'endocrine therapy', 'fracture', 'gonadotropin-releasing hormone', 'osteoporosis', 'selective oestrogen receptor modulators', 'tamoxifen' or 'ovarian function suppression'. Only material relevant to the use of adjuvant endocrine therapy for early breast cancer was included; hence, material pertaining to metastatic breast cancer was excluded. Only full-text articles, published in English, were reviewed.

\section{Biosynthesis of oestrogens and mechanisms of endocrine therapy in early breast cancer}

There is accumulating evidence from animal, epidemiological and in vitro studies, that endogenous oestrogens play a causal role in the development of breast cancer and its progression (Althuis et al. 2004). Endocrine therapy attempts to prevent proliferative oestradiol receptor signalling by either inhibiting binding of oestradiol to its receptor or reducing the concentration of oestradiol.

\section{Biosynthesis of oestrogens}

Oestrogens are highly conserved steroid hormones which occur in three main forms: oestrone (E1), 17 $\beta$-oestradiol (E2) and oestriol (E3). In premenopausal women, the primary source of oestrogens comes from ovarian production which accounts for $>90 \%$ of circulating E2, the principal and most potent (biologically active) oestrogen secreted. In postmenopausal women, extra-ovarian production of oestrogens becomes predominant, particularly in stromal adipose tissue (Silva et al. 2008), and serum E1 and E2 concentrations fall by approximately 75 and $90 \%$ respectively (Albright et al. 1941). In postmenopausal women, E1 is the main circulating oestrogen but has weak oestrogenic effects and requires conversion to $\mathrm{E} 2$ in order to maximise its effects. E3 is the most prevalent oestrogen in the maternal circulation during pregnancy but exists in extremely low concentrations in the non-pregnant state. A fourth oestrogen, oestetrol (E4), thought to be synthesised exclusively by the foetal liver, is a weak oestrogen with detectable concentrations only during pregnancy. Its biological function is currently unknown.

Ovarian production of oestrogens begins with androgen synthesis in the theca cells and ends with conversion of these androgen substrates to oestrogens by the enzyme aromatase in the granulosa cells. In the theca cells, luteinising hormone (LH) signalling stimulates the expression of steroid-synthesising enzymes that convert cholesterol to the androgens, androstenedione and testosterone (T). In the granulosa cells, follicle-stimulating hormone (FSH) signalling stimulates the expression of aromatase which converts these androgen substrates to oestrogens: androstenedione to E1 and T to E2. Aromatase (CYP19), encoded by the CYP19A1 gene (Evans et al. 1986), is the only known enzyme responsible for the synthesis of oestrogens from androgenic substrates. In healthy humans, aromatase is highly expressed in the placenta and granulosa cells of ovarian follicles but also expressed at lower levels in several other tissues which include the stroma of adipose tissue, muscle, bone, adrenal glands, breast tissue and brain. Other key enzymes involved in the biosynthesis of oestrogens are the $17 \beta$ hydroxysteroid dehydrogenases responsible for interconversion of androstenedione and $\mathrm{T}$ and of E1 and E2 and steroid sulphatase which catalyses the conversion of oestrone sulphate (inactive form) to E1 (active form) (Fig. 1).

Extra-ovarian synthesis of oestrogens, the predominant source of oestrogens in postmenopausal women, differs from ovarian synthesis in a few distinct ways. First, the majority https://joe.bioscientifica.com

https://doi.org/10.1530/JOE-19-0077
(C) 2019 Society for Endocrinology Published by Bioscientifica Ltd.
Printed in Great Britain 


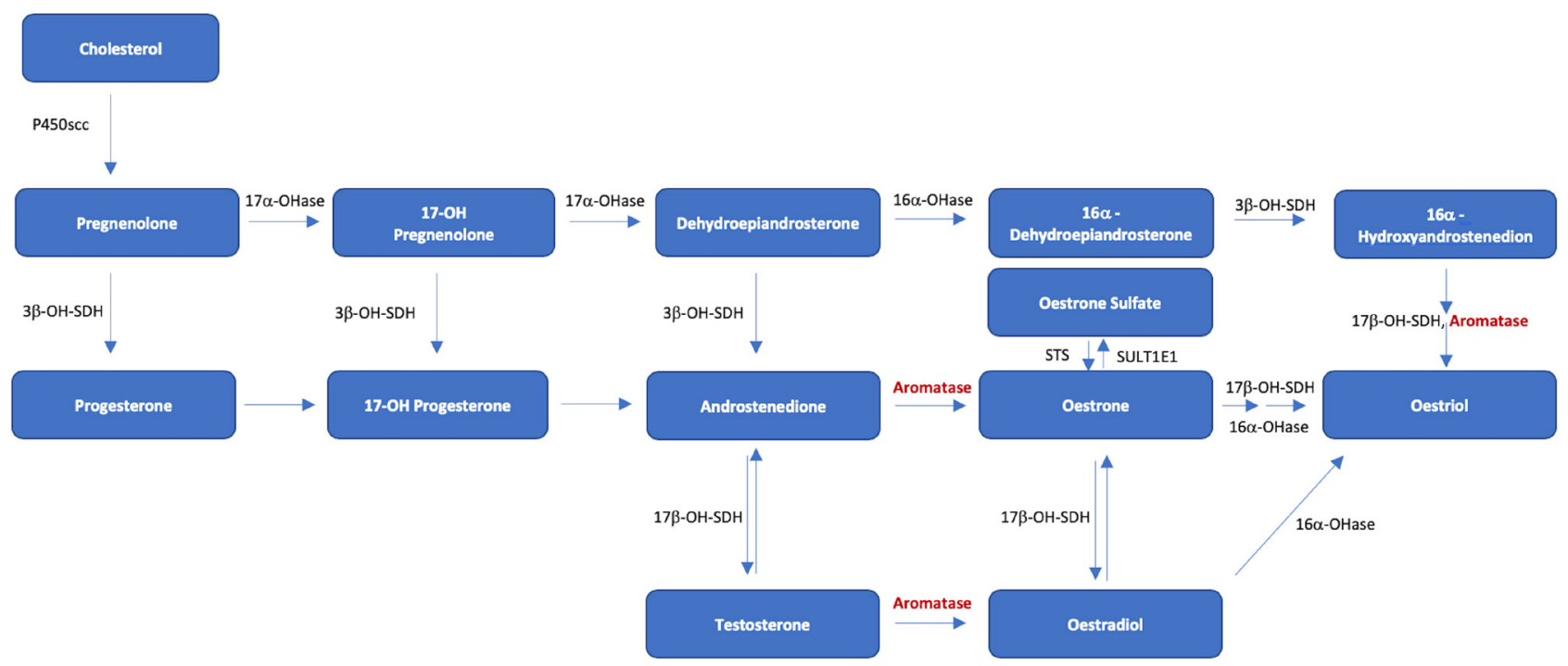

\section{Figure 1}

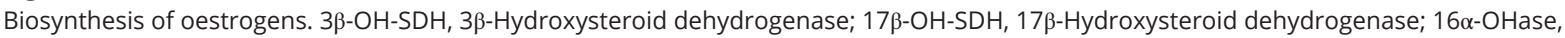
16 $\alpha$-Hydroxylase; $17 \alpha-$ OHase, 17 $\alpha$-Hydroxylase; STS, steroid sulfatase; SULT1E1, oestrogen sulfotransferase.

of extra-ovarian tissues are unable to convert cholesterol to C19 precursors (androgens) required for oestrogen synthesis (Labrie et al. 1997, 1998). Therefore, extra-ovarian synthesis of oestrogens is dependent on the availability and cellular uptake of circulating androgens primarily derived from the adrenal glands. There is also tissue-specific variation in the distribution of enzymes involved in the synthesis and metabolism of oestrogens so local concentrations of oestrogens vary between tissues. Second, in contrast to ovarian secreted oestrogens that circulate to distal target tissues to exert their effects, oestrogens produced in extraovarian tissues mainly exert their effects, in a paracrine or autocrine fashion (Simpson et al. 2000), at the local tissue level in which they are produced. Metabolism of oestrogens also occurs locally which limits their systemic effects. Hence, whilst the total circulating concentration of oestrogens produced after menopause is relatively small, the tissue concentrations may be high and influence biological actions locally. This may have implications for inferences made from clinical studies in postmenopausal women regarding the biological actions of E2, as most of these studies infer biological actions from circulating E2 concentrations that may not account for local tissue concentrations.

\section{Mechanisms of adjuvant endocrine therapy}

Current adjuvant endocrine therapies inhibit the proliferative effect of oestradiol signalling in breast tissue in one of the two ways - they either competitively inhibit binding of oestradiol to the ER in breast tissue (selective oestrogen receptor modulators (SERMs), most commonly tamoxifen) or they reduce the concentration of oestradiol by blocking aromatase (AIs). AIs can be divided into two groups based on their mode of action - type 1 inhibitors are steroid analogues of androstenedione that bind irreversibly to aromatase, whereas type 2 inhibitors are nonsteroidal and bind reversibly to the heme group of aromatase. The three approved AIs currently in use are the type 1 inhibitor, exemestane, and the type 2 inhibitors, letrozole and anastrozole.

The choice of endocrine therapy depends on menopausal status, cancer characteristics and contraindications to a particular type of treatment. In premenopausal women, where $>90 \%$ of circulating oestradiol comes from the ovaries, irreversible suppression of ovarian function is achieved by surgical bilateral oophorectomy or radiation to the ovaries. Alternatively, reversible ovarian function suppression (OFS) can be achieved chemically with the use of GnRH analogues that suppress pituitary gonadotropin secretion, thereby decreasing ovarian oestradiol production (Nourmoussavi et al. 2017). In postmenopausal women, the low concentrations of circulating oestrogens are still sufficient to exert biological effects on ER-expressing breast cancer cells. AIs are able to block this low level of extra-ovarian aromatase and suppress concentrations of circulating oestrogens to almost undetectable levels (Geisler et al. 1996). In premenopausal women, the sole use of AIs results in an initial relative decrease in circulating oestradiol which inhibits the oestradiol mediated negative feedback 
on gonadotropin production. This causes activation of the hypothalamic-pituitary-gonadal axis, thereby increasing both ovarian androgen production and aromatase activity which ultimately increases oestradiol concentration (Simpson \& Santen 2015). As such, use of AIs in premenopausal women is contraindicated, unless there is concurrent OFS. Tamoxifen, the most commonly used selective oestrogen receptor modulator, acts as an ER antagonist in breast tissue and is effective irrespective of circulating oestradiol concentration. It can therefore be used as monotherapy in both pre- and postmenopausal women (Maximov et al. 2013).

\section{Clinical use and oncologic benefits of adjuvant endocrine therapy}

The American Society of Clinical Oncology, along with other international societies, recommends the use of endocrine therapy in all women with ER-positive early breast cancer (Burstein et al. 2014). There are two important considerations when making adjuvant endocrine therapy decisions: (i) which drug to select at the commencement of endocrine therapy (which is intended for 5-year duration) and (ii) whether to extend endocrine therapy beyond 5 years, and if so, whether to continue the same agent or switch. Extending adjuvant endocrine therapy beyond 5 years is becoming the standard of care for some patients, although identifying those patients with a risk of late relapse remains an area of intense research activity.

\section{Postmenopausal women}

In postmenopausal women, AIs are preferred over tamoxifen and are used as monotherapy or sequential therapy after tamoxifen. In a meta-analysis of 9855 women with ER-positive early breast cancer, 10-year breast cancer mortality was lower in women treated with an AI for 5 years compared to women treated with tamoxifen for five years $(12.1 \%$ vs $14.2 \%$, relative risk (RR) 0.85 ; 95\% CI 0.75-0.96) (Early Breast Cancer Trialists' Collaborative Group 2015b). The difference in mortality benefit between an AI and tamoxifen is modest compared to the larger $9.2 \%$ difference in 15-year breast cancer mortality between tamoxifen and placebo (RR 0.70; 95\% CI 0.64-0.75) (Early Breast Cancer Trialists' Collaborative Group 2011); hence, tamoxifen is still a reasonable alternative when an AI is contraindicated or not tolerated.

Tamoxifen given for 10 compared to 5 years is preferred due to improved disease-free and overall survival (Davies et al. 2013). More recent evidence from multiple randomised controlled trials have addressed the question of whether extending AI therapy for a further 5 years reduces the risk of recurrence in women who have received AI therapy as part of their initial 5 years of adjuvant treatment. Results from the MA.17R, DATA and NSABP B-42 trials have all demonstrated modest improvements in disease-free survival of 2-4\% with no differences in overall survival (Goss et al. 2016, Tjan-Heijnen et al. 2017, Mamounas et al. 2019). Based on subset analyses, women at greater risk of recurrence according to their clinicopathological features derived a larger benefit than women at lower risk. In women who received extended AI therapy, there was an increased risk of AI-induced toxicities which led to decreased compliance (Goss et al. 2016). In the MA.17R study, there was almost a doubling in the rate of osteoporosis (11 vs 6\%) and a 3.5\% absolute increase in fracture rates despite approximately 1 in 2 women receiving treatment with bisphosphonates (Goss et al. 2016). These findings are consistent with a recent systematic review of 16,349 women, which demonstrated increased odds of fracture (odds ratio (OR) 1.34; 95\% CI 1.16-1.55) with AI treatment beyond 5 years (Goldvaser et al. 2018). As such, the use of extended AI therapy is largely considered only in women who have high-risk disease and/or in those with minimal AI-induced toxicity.

\section{Premenopausal women}

Until recent years, the standard of care of premenopausal women has been to use upfront tamoxifen and if they remain premenopausal at 5 years, then extending tamoxifen to 10 years is an option as evidence from the aTTom and ATLAS trials (Gray et al. 2013, Davies et al. 2017). However, in those with high-risk disease, based on a number of clinicopathological characteristics such as younger age, large tumour size and lymph node involvement, recent evidence has demonstrated more favourable oncological outcomes with the use of concurrent OFS with tamoxifen or aromatase inhibition (Burstein et al. 2016). Evidence for this approach comes from the combined analysis of two pivotal International Breast Cancer Study Group (IBCSG) initiated phase III randomised controlled trials (RCTs), SOFT and TEXT (Regan et al. 2013). In these trials, approximately 6000 premenopausal women were randomised to 5 years of tamoxifen monotherapy or concurrent OFS with either tamoxifen or AI (exemestane) in SOFT and to OFS with either tamoxifen or AI (exemestane) in TEXT (Regan et al. 2013).

Results of the 8-year follow-up of these two trials have recently been published (Francis et al. 2018). In SOFT, 8-year disease-free survival rates were $78.9 \%$ with 
tamoxifen alone, 83.2\% with OFS + tamoxifen (hazard ratio (HR) 0.76 ; 95\% CI $0.62-0.93$ vs tamoxifen alone) and $85.9 \%$ with OFS + AI (HR 0.65; 95\% CI 0.53-0.81 vs tamoxifen alone) (Francis et al. 2018). The rate of overall survival at 8 years was $91.5 \%$ with tamoxifen alone, 93.3\% with OFS + tamoxifen (HR 0.67; 95\% CI 89.4-93.2 vs tamoxifen alone) and 92.1\% with OFS + AI (HR 0.85; 95\% CI 0.62-1.15 vs tamoxifen alone) (Francis et al. 2018). In the combined analysis of SOFT and TEXT, which included all women receiving OFS randomised to either tamoxifen or AI, 8-year disease-free survival rates were $86.8 \%$ with OFS + AI compared to $82.8 \%$ with OFS + tamoxifen (HR 0.77; 95\% CI 0.67-0.90). Despite these improvements in disease-free survival, with OFS + AI compared to OFS + tamoxifen, there is no proven evidence of a survival advantage with the use of OFS + AI compared to OFS + tamoxifen at 8 years; overall survival rates were 93.4 and $93.3 \%$ respectively (HR 0.98, 95\% CI 0.79-1.22) (Francis et al. 2018). Additionally, use of OFS + AI, compared to OFS + tamoxifen, had higher rates of adverse events, including a higher incidence of osteoporosis (14.8 vs 7.2\%) (Francis et al. 2018). Clinicians will therefore need to consider the benefits versus the toxicities of this more aggressive treatment strategy on an individualised basis.

\section{Oestradiol deficiency and bone loss}

Oestradiol is an important regulator of bone metabolism and oestradiol deficiency, such as that produced by menopause, is an important determinant of bone loss, microstructural deterioration and bone fragility (Albright et al. 1941, Riggs et al. 2002).

Bone modelling and remodelling are the two processes that determine bone's external size, shape and its internal microstructure. Bone modelling is the deposition of bone on a quiescent surface of bone and is responsible for changing the size and shape of bone. Bone remodelling, carried out by teams of cells forming basic multicellular units (BMUs), is responsible for maintaining the material composition of bone (Frost 1964). Osteoclasts of a BMU resorb a volume of bone at a given location and this is followed by a lag or reversal phase and then a phase of bone formation carried out by osteoblasts. Bone formation is characterised by the much slower deposition of osteoid which undergoes rapid primary and then much slower secondary mineralisation to become bone (Boskey 2002, Akkus et al. 2003, 2004). The resorptive phase takes $\sim 3$ weeks (Eriksen et al. 1984b), the reversal phase $\sim 5$ weeks (Eriksen et al. 1984b) and the formation phase $\sim 3$ months (Tran Van et al. 1982, Eriksen et al. $1984 a$ ) with mineralisation taking months if not years to reach completion (Boskey 2002, Akkus et al. 2003, 2004).

To maintain bone mass at the same level, the bone formed in each BMU must replace precisely the amount removed by resorption within that BMU. In states of oestradiol deficiency, bone remodelling becomes unbalanced and rapid. There is a net decrease in the amount of bone deposited by each BMU and an increase in the rate of bone remodelling, i.e., greater numbers of BMUs, each deposit less bone than they remove producing a net bone loss and microstructural deterioration (Lips et al. 1978, Vedi et al. 1983-1984, Eriksen 1986). The molecular and cellular mechanisms by which the skeletal effects of oestradiol deficiency are mediated are complex and incompletely understood. These mechanisms are reviewed in Almeida et al. (2017) and Khosla \& Monroe (2018).

Unbalanced and rapid remodelling causes bone loss and structural deterioration of both trabecular and cortical bone. Increased resorption depth upon trabeculae cause them to perforate and become disconnected (Hernandez et al. 2006). Resorption of cortical bone initiated at points upon the surfaces of Haversian canals causes them to enlarge, coalesce and fragment the cortex. The microstructural deterioration of the reduced bone volume compromise bone strength out of proportion to the bone loss producing it and increase the risk of fragility fractures (Schaffler \& Burr 1988, Hernandez et al. 2006) (Fig. 2).

\section{Endocrine therapy and bone health}

Endocrine therapy, apart from tamoxifen in postmenopausal women, causes relatively rapid decreases in circulating oestradiol concentrations or competitively inhibits oestradiol action in bone, adversely affecting bone health in the majority of women with early breast cancer.

\section{Selective oestrogen receptor modulators}

In contrast to its action as a pure ER antagonist in breast tissue, SERMs, most commonly tamoxifen, act as partial ER agonists in bone and their actions depend on menopausal status as tamoxifen is less potent than native oestradiol (Maximov et al. 2013).

In postmenopausal women where endogenous oestradiol concentrations are low, tamoxifen acts as a 
Premenopausal Control

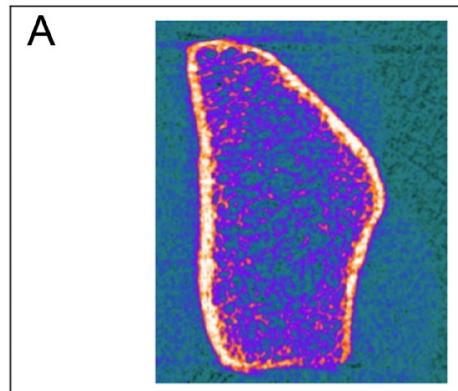

B

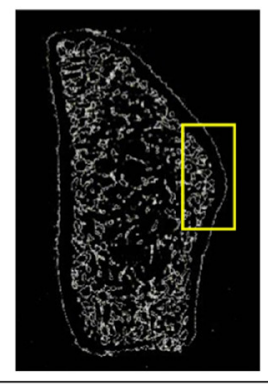

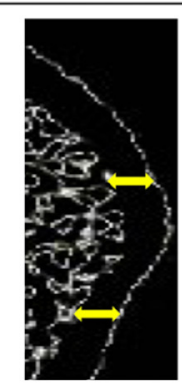

Case
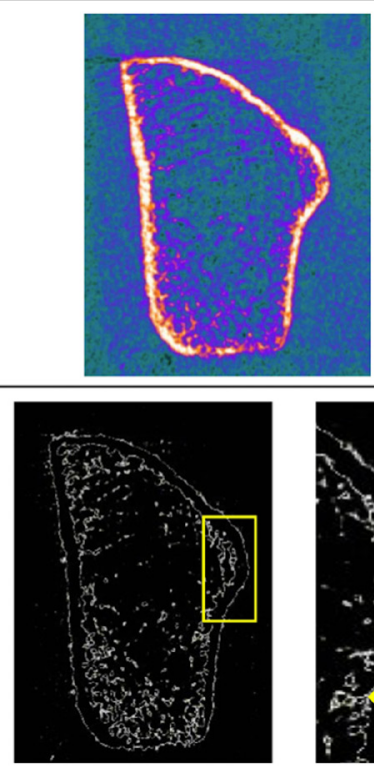

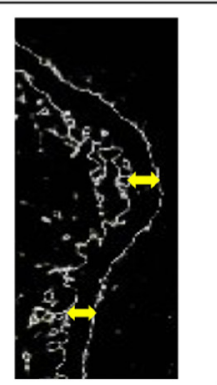

\section{Figure 2}

Effect of oestradiol deficiency on bone structure. Representative cross-sectional high-resolution peripheral quantitative computed tomography images of the distal radius in an age-matched healthy premenopausal woman (control - left panel) and a premenopausal woman with ER-positive early breast cancer treated with concurrent ovarian function suppression and aromatase inhibition (case-right panel). Panel A: Loss of trabecular number and increased trabecular separation in the case compared to the control. Panel B: Increased bone resorption at the cortico-medullary interface resulting in thinning and fragmentation of the cortex. partial agonist in bone, preventing bone loss and reducing fracture risk. In a small study of 140 postmenopausal women, tamoxifen modestly increased annual lumbar spine bone mineral density (BMD) by $0.6 \%$ compared to a $1.0 \%$ decrease in the placebo group (Love et al. 1992). In the National Surgical Adjuvant Breast and Bowel Project P-1 Study, 13,388 women deemed high risk of developing breast cancer were randomised to 5 years of tamoxifen $20 \mathrm{mg}$ daily or placebo (Fisher et al. 2005). After a 7-year follow-up period, women treated with tamoxifen for 5 years had a $32 \%$ reduction in osteoporotic fractures compared to placebo (RR 0.68; 95\% CI 0.51-0.92) (Fisher et al. 2005). This is in contrast to findings of a recent meta-analysis that reported similar fracture risk in women with breast cancer treated and not treated with tamoxifen (pooled risk ratio 0.95; 95\% CI 0.84-1.07) (Tseng et al. 2018).

In premenopausal women in whom circulating oestradiol concentrations are high, tamoxifen acts as a partial antagonist in bone, competing with oestradiol for the ER-binding sites and causes bone loss (Powles et al. 1996). In a 3-year placebo-controlled prospective study, the average annual loss in lumbar spine BMD in premenopausal women treated with tamoxifen was $1.4 \%$ compared to a $0.2 \%$ gain with placebo. However, when combined with the GnRH analogue goserelin, which significantly reduces circulating oestradiol concentration by $>90 \%$, tamoxifen appeared to mitigate the bone loss associated with goserelin induced OFS (Sverrisdottir et al. 2004). In a 2-year RCT of 89 women, total body BMD decreased by $5.0 \%$ with goserelin monotherapy compared to $1.4 \%$ with combined goserelin and tamoxifen (Sverrisdottir et al. 2004).

\section{Aromatase inhibitors}

Postmenopausal women treated with AIs, compared to age-matched women, have increased bone remodelling, accelerated bone loss and increased fracture rates. Although preclinical studies have suggested a bone sparing effect of exemestane, due to its androgenic structure, compared to letrozole (Goss et al. 2004), the few clinical studies that have compared the effects of different AIs on bone, have not revealed any significant differences amongst them (Goss et al. 2014, Smith et al. 2017).

In a systematic review based meta-analysis of 30,023 postmenopausal women from seven RCTs, there was a $47 \%$ increased fracture risk in women treated with AIs compared to tamoxifen (OR 1.47; 95\% CI 1.34-1.61) (Amir et al. 2011). Fracture incidence was $7.5 \%$ and $5.2 \%$ in the $\mathrm{AI}$ and tamoxifen group respectively, with a number needed to harm of 46 (Amir et al. 2011). However, the absence of studies that investigated the effect of these endocrine therapies on fracture risk as an adjudicated primary endpoint, the lack of placebo control groups, and the potential beneficial effects of tamoxifen on bone in postmenopausal women make interpretation problematic. Indeed, in a dedicated fracture endpoint trial in 3420 postmenopausal women, approximately 1 in 10 women had an incident clinical fracture within three years of 
AI treatment (Gnant et al. 2015), comparable to fracture rates reported in untreated women 5-10 years older with established osteoporosis (Lyles et al. 2007, Cummings et al. 2009). The much higher fracture incidence in this study compared to reports from the majority of primary AI efficacy trials is consistent with under-reporting of fracture outcomes in these oncology endpoint trials. A systematic review based meta-analysis combining RCTs and cohort studies, estimated a 17\% (95\% CI 1.07-1.28) increase in fracture risk in women treated with AIs compared to untreated women (Tseng et al. 2018). In another recent meta-analysis that compared treatment toxicities in 16,349 postmenopausal women who either received extended AI therapy after an initial five years of AI or placebo/no treatment after an initial five years of AI (Goldvaser et al. 2018), extended AI treatment was associated with increased odds of clinical fractures (OR 1.34; 95\% CI 1.16-1.55) (Goldvaser et al. 2018).

In premenopausal women, as discussed earlier, AIs cannot be used without concurrent OFS. Combined use of OFS and AI in premenopausal women results in a profound reduction in oestradiol concentration and produces the largest magnitude of bone loss in women receiving endocrine therapy. In general, although direct comparisons cannot be made across studies, relative rates of bone loss, as measured by dual-energy x-ray absorptiometry (DXA), are highest in premenopausal women with the greatest degree of oestradiol suppression. Rates of annual BMD loss at the lumbar spine have been reported to be $5.6 \%$ with OFS + tamoxifen (Gnant et al. 2008), 8.2\% with GnRH monotherapy (Fogelman et al. 2003), and 9.3\% with OFS+AI (Gnant et al. 2008). In the SOFT and TEXT trials, use of OFS + AI was associated with a two-fold increase in the prevalence of osteoporosis compared to OFS + tamoxifen (13.2 vs $6.4 \%$ at 68 months) (Pagani et al. 2014). In a small cross-sectional study of premenopausal women (mean age 43 years) with early breast cancer treated with OFS + AI for a median duration of 17 months (range 6-120), cortical and trabecular volumetric BMD, assessed by highresolution peripheral quantitative computed tomography (HR-pQCT), was markedly reduced compared to healthy age-matched controls and similar to women 20 years older who were at least 10 years post natural menopause (Ramchand et al. 2017).

A small number of clinical trials have reported increases in BMD in premenopausal women who resume menstrual function after cessation of OFS + AI (Gnant et al. 2008) and in postmenopausal women after cessation of AI (Geisler et al. 2006). Use of bone densitometry obscures the differing behaviour of bone matrix volume and matrix mineralisation and may produce misleading information. It is not known if the increase in BMD, observed after cessation of aromatase inhibition, is due to an increase in bone matrix volume or an increase in matrix mineralisation of the existing volume. It is more likely that cessation of aromatase inhibition reduces the bone remodelling rate, allowing for increased mineralisation of the less frequently remodelled matrix volume as opposed to an accrual of matrix volume (Seeman 2010). The effects on bone strength and fracture risk are also not known but will differ depending on the underlying process causing the increase in BMD.

\section{Management of bone health in women receiving endocrine therapy}

Several guidelines and position statements regarding the assessment and management of bone health in women with ER-positive early breast cancer treated with endocrine therapy have been developed by international societies (Gralow et al. 2013, Paterson \& Shea-Budgell 2013, Coleman et al. 2014, Juozaityte et al. 2014, Singapore Cancer Network Breast Cancer 2015, Hadji et al. 2016, 2017, Tremollieres et al. 2017, Grossmann et al. 2018).

\section{Evaluation and monitoring}

All women commencing AIs and premenopausal women commencing tamoxifen should have a baseline evaluation of their fracture risk. This should include a detailed history, physical examination, laboratory evaluation and BMD assessment by DXA, to screen for risk factors for fracture. Standard risk factors for osteoporosis include advancing age, prevalent fragility fractures, parental history of hip fracture, low body mass index, tobacco smoking, excessive alcohol consumption, chronic glucocorticoid use and inflammatory joint conditions such as rheumatoid arthritis. Assessment for morphometric vertebral fractures by thoraco-lumbar $\mathrm{x}$-ray may be considered in postmenopausal women and premenopausal women with low BMD (T or Z score <-1.5) (Bouvard et al. 2012, Pedersini et al. 2017). Use of conventional fracture risk assessment tools such as FRAX and the GARVAN Fracture Risk Calculator may underestimate fracture risk as they do not account for AI therapy or chemotherapy. These tools are also not validated for use in women less than 40 years of age.

There is no high level evidence to guide the optimal approach to monitor women receiving endocrine therapy. 
Assessment of BMD in untreated women should be performed at baseline and may be considered 12 months after starting endocrine therapy with subsequent scans determined on an individualised basis, depending on the presence of clinical risk factors for osteoporosis and baseline BMD values (Grossmann et al. 2018). For women treated with antiresorptive therapy, BMD should be assessed at baseline and every two years or less frequently. If there are major changes to clinical status, treatment or significant declines in BMD (annual BMD loss $\geq 5 \%$ and/or $\geq 0.05 \mathrm{~g} / \mathrm{cm}^{2}$ ), women should be re-evaluated and in those women with a decline in BMD, additional assessment regarding treatment adherence, drug absorption and causes of secondary osteoporosis should be undertaken.

\section{Treatment}

All women should be advised to adopt lifestyle changes that promote skeletal and overall health. Extrapolating from evidence outside of the breast cancer population given the paucity of evidence specific to women with breast cancer, weight bearing exercise, which includes impact and resistance training, adequate daily calcium intake preferably through dietary sources, vitamin D sufficiency and smoking cessation are routinely recommended.

Similar to recommendations for the general female population, antiresorptive therapy should be commenced in all women with pre-existing fragility fractures and in women 70 years and older who have evidence of osteoporosis on BMD (defined as a T-score $<-2.5$ s.D.). Outside of these criteria, the optimal threshold at which to commence bone-modifying therapy is unclear. Most guidelines, largely based on expert opinion, would recommend commencing antiresorptive therapy in postmenopausal women with T-scores (or Z-scores if 50 years or younger) less than -2.0 at any site, if annual $\mathrm{BMD}$ loss is $\geq 5 \%$ and/or $\geq 0.05 \mathrm{~g} / \mathrm{cm}^{2}$, considering baseline BMD and other risk factors for fracture, or in those with increased absolute fracture risk based on the presence of other clinical risk factors other than BMD. In premenopausal women, there is very limited evidence to guide accurate assessment of fracture risk or long-term effects of antiresorptive therapy on skeletal health. The potential for future maternity also needs to be taken into account if antiresorptive therapy is being considered.

\section{Antiresorptive therapy}

Postmenopausal women The Food and Drug Administration (FDA) approved antiresorptive therapies for postmenopausal osteoporosis also have proven efficacy in slowing or preventing AI-induced bone loss in postmenopausal women, based largely on BMD studies (see Grossmann et al. 2018 for summary). Of these therapies, zoledronic acid is the best studied. There is limited data on the anti-fracture efficacy of antiresorptive therapies with most bisphosphonate trials underpowered to assess fracture prevention and only one trial examining the effect of denosumab, a RANK-ligand inhibitor, on fracture outcomes (Gnant et al. 2015). In this study, denosumab $60 \mathrm{mg}$ given 6 monthly, halved the clinical fracture risk at 36 months (estimated fracture rates in the denosumab group 9.6 vs $5.0 \%$ in the placebo group) (Gnant et al. 2015). The predominant sites of fracture were the forearm and hands ( 2.6 vs $1.5 \%$ in the placebo and denosumab groups respectively) followed by the vertebrae (1.5 vs $1.0 \%$ in the placebo and denosumab groups) (Gnant et al. 2015). Benefits in fracture risk reduction with denosumab appeared similar irrespective of baseline BMD values although the study may have been underpowered for this analysis (Gnant et al. 2015) (Table 1).

Four independent trials (ZO-FAST, Bundred et al. 2008; Z-FAST, Brufsky et al. 2007; E-ZO-FAST, Llombart et al. 2012; NCCTG-NO3CC, Hines et al. 2009) evaluated the effects of giving zoledronic acid $4 \mathrm{mg}$ 6-monthly at the start of AI therapy or delaying treatment. These studies all demonstrated beneficial effects on BMD with upfront compared to delayed therapy. In the largest study, ZO-FAST, approximately 1000 postmenopausal women were randomised to receive zoledronic acid $4 \mathrm{mg}$ 6-monthly when they started AI therapy or treatment was delayed until the women either had a fragility fracture or on study T-score <-2.0 SD (Bundred et al. 2008). At 12 months, lumbar spine BMD, the primary endpoint of the study, increased by $2.1 \%$ in the women who received immediate treatment compared to a $3.5 \%$ decrease in those who received delayed treatment. At 5-year follow-up of the study, there were persistent beneficial effects on BMD in women who received immediate zoledronic acid compared to those who received delayed treatment (lumbar spine BMD increased by $4.3 \%$ in the immediate group and decreased by $5.4 \%$ in the delayed group, $P<0.0001$ ) (Coleman et al. 2013). Three-year fracture incidence was similar between the two groups (26 (5.0\%) in the immediate group and 32 (6.0\%) in the delayed group, $P=0.502$ ) (Eidtmann et al. 2010). However, this study was not designed to assess fracture outcomes as a primary endpoint and may be underpowered to detect any differences in fracture incidence between the two groups. There were three confirmed and two possible 
Table 1 Antiresorptive agents used to treat bone loss in postmenopausal women with ER-positive early breast cancer treated with aromatase inhibitors.

\begin{tabular}{|c|c|c|c|c|c|}
\hline Agent & Dose and frequency & Route & Prevents/reduces BMD loss & $\begin{array}{l}\text { Proven anti-fracture } \\
\text { efficacy }\end{array}$ & $\begin{array}{l}\text { Proven oncological } \\
\text { benefit }\end{array}$ \\
\hline Alendronate & $70 \mathrm{mg}, \mathrm{QW}$ & $\mathrm{PO}$ & Yes & No & No \\
\hline Clodronate & $1600 \mathrm{mg}, \mathrm{QD}$ & $\mathrm{PO}$ & Yes & No & Yes \\
\hline Ibandronate & 150 mg, Q4W & $\mathrm{PO}$ & Yes & No & No \\
\hline Risedronate & 35 mg, QW & $\mathrm{PO}$ & Yes & No & No \\
\hline Zoledronic Acid & $4 \mathrm{mg}, \mathrm{Q} 6 \mathrm{M}$ & IV & Yes* & No & Yes \\
\hline Denosumab & 60 mg, Q6M & SC & Yes & Yes & No \\
\hline
\end{tabular}

Data are based on evidence from randomised controlled trials and meta-analyses. All data are specific to postmenopausal women treated with aromatase inhibitors unless otherwise specified.

*Zoledronic acid 4 mg Q6M prevents BMD loss in both postmenopausal women treated with aromatase inhibitors and premenopausal women treated with concurrent OFS + Al.

BMD, bone mineral density; IV, intravenous; PO, per oral; SC, subcutaneous.

cases (insufficient data) of osteonecrosis of the jaw (ONJ) in women receiving zoledronic acid (Coleman et al. 2013).

Premenopausal women In premenopausal women, there are very few studies evaluating the efficacy of antiresorptive therapy in preventing endocrine therapy induced bone loss and no studies assessing fracture outcomes. In the largest RCT of 404 women, the efficacy of zoledronic acid in preventing BMD loss at 36 months was assessed (Gnant et al. 2008). In this study, women were treated with OFS and either tamoxifen or AI. In each of the OFS + tamoxifen and OFS + AI groups, women were randomised to receive either zoledronic acid $4 \mathrm{mg}$ 6-monthly or placebo. At 36 months, lumbar spine BMD decreased in women receiving placebo by $9.0 \%$ (mean difference $-0.095 \mathrm{~g} / \mathrm{cm}^{2}(-0.134$ to -0.057$\left.), P<0.0001\right)$ and $13.6 \%$ (mean difference $-0.067 \mathrm{~g} / \mathrm{cm}^{2}(-0.179$ to -0.102$)$, $P<0.0001)$ in the OFS +tamoxifen and OFS + AI groups respectively, whilst women treated with zoledronic acid had stable BMD at 36 months (Gnant et al. 2008). There were no adjudicated cases of $\mathrm{ONJ}$ in this premenopausal cohort of women treated with zoledronic acid $4 \mathrm{mg}$ every 6 months for a duration of 3 years (Gnant et al. 2008).

\section{Duration of therapy}

Evidence regarding the optimal duration of antiresorptive therapy specific to women with early breast cancer receiving endocrine therapy is lacking. Most guidelines suggest treatment cessation at the completion of endocrine therapy unless high fracture risk persists. Given that in contrast to bisphosphonates, denosumab is not retained in bone, soon after cessation of treatment, there is a rapid rise in bone remodelling, a decline in BMD and, although the absolute risk is low, an increased risk of multiple vertebral fractures (Bone et al. 2011, Miller et al. 2011). Post hoc analysis of the large denosumab trials, FREEDOM and FREEDOM Extension, showed that women at the greatest risk of developing multiple vertebral fractures were those who had a prior vertebral, either before or during treatment (Cummings et al. 2018). Additionally, preclinical data have demonstrated the importance of the bone microenvironment in cancer progression and increased bone remodelling has been shown to release factors that stimulate tumour growth (Croucher et al. 2016). Therefore, current expert opinion recommends that delays in subsequent dosing of denosumab should be avoided and that cessation of denosumab is consolidated with a bisphosphonate (Tsourdi et al. 2017, Chukir et al. 2018). Data regarding optimal route, duration and timing of bisphosphonate therapy after cessation of denosumab is currently under investigation.

\section{Anti-cancer role of antiresorptive drugs}

The importance of the bone microenvironment in cancer development and progression is now widely recognised. Through a number of complex mechanisms, which remain incompletely understood, tumour cells lie dormant in bone and in some cases reactivate to produce metastasis (Croucher et al. 2016). Remodelling of the endosteal bone surface is thought to be one mechanism by which dormant tumour cells are reactivated (Croucher et al. 2016). The efficacy of adjuvant zoledronic acid and oral bisphosphonates, which slow bone remodelling, in preventing disease recurrence has been evaluated in a number of small breast cancer clinical trials. With the exception of a few studies, these trials were predominantly negative for this outcome. However, the patient-level meta-analysis conducted by the Early Breast Cancer Trialists Collaborative Group (EBCTG), which predominantly included studies that evaluated clodronate or zoledronic acid with very limited data for other bisphosphonates, demonstrated that in the sub-group 
of women who were postmenopausal (either natural or iatrogenic), both zoledronic acid (4mg 6-monthly) and clodronate reduced breast cancer mortality (RR 0.82; 95\% CI 0.73-0.93) and bone recurrence (RR 0.72; 95\% CI 0.60-0.86) (Early Breast Cancer Trialists' Collaborative Group 2015a). No beneficial effects on mortality or breast cancer recurrence were noted in the premenopausal subgroup (Early Breast Cancer Trialists' Collaborative Group 2015a). The difficulty with extrapolating the results of this meta-analysis to clinical care was the observation that all postmenopausal women, irrespective of their ER or lymph node status, appeared to benefit from adjuvant zoledronic acid or clodronate, making it difficult to select women for whom this treatment would be most beneficial.

Although there was a signal of improved disease-free survival in the intention to treat analysis of the ABCSG-18 trial (Gnant et al. 2015), a fracture outcome trial where postmenopausal women were randomised to denosumab $60 \mathrm{mg}$ 6-monthly or placebo for a 3-year period, results of the recently completed but not yet peer-reviewed phase III D-CARE trial (Coleman et al. 2018) were in contradiction to these findings. In the D-CARE trial, the dosing regimen of denosumab differed significantly from the ABCSG-18 trial. In D-CARE, postmenopausal women with ER-positive early breast cancer received $120 \mathrm{mg}$ of denosumab or matching placebo every month for 6 months and then every 3 months for up to 5 years (Coleman et al. 2018). After median follow-up of 67 months, there were no reductions in bone metastasisfree survival (BMFS), breast cancer recurrence, or mortality in postmenopausal women treated with denosumab compared to placebo (Coleman et al. 2018). Whilst this was a negative study for its primary outcome (BMFS), exploratory analysis suggested benefit with denosumab for time to bone metastasis as first recurrence (HR 0.76; 95\% CI 0.59-0.97) (Coleman et al. 2018). These findings were unexpected as denosumab is thought to be a more potent inhibitor of bone remodelling compared to zoledronic acid or clodronate. As anticipated, given the higher cumulative doses of denosumab in the D-CARE trial, incidence rates of $\mathrm{ONJ}$ and atypical femoral fractures (AFF) were higher in D-CARE compared to ABCSG-18. In D-CARE, ONJ occurred in $122(5.4 \%)$ women treated with denosumab compared to $4(0.2 \%)$ women receiving placebo and AFF only occurred in women receiving denosumab, $n=9$ (0.4\%) (Coleman et al. 2018). There were no independently adjudicated cases of ONJ and or confirmed AFF in ABCSG-18 (Gnant et al. 2015).

Expert societies, including the American Society of Clinical Oncology, currently recommend the use of zoledronic acid $4 \mathrm{mg}$ 6-monthly or clodronate as adjuvant treatment in postmenopausal women with early breast cancer, outside of their role in maintaining bone health and preventing fractures (Dhesy-Thind et al. 2017). The absolute oncological benefits appear to be greater in women who are at higher risk of breast cancer recurrence and almost all women included in the trial data supporting this recommendation had received systemic therapy (Dhesy-Thind et al. 2017).

\section{Anabolic therapy}

Currently available anabolic agents, teriparatide and abaloparatide, are not approved for use in women with breast cancer due to theoretical concerns of stimulating cancer cell progression. Additionally, in women who are treated with radiotherapy where the field of radiation includes the ribs, teriparatide cannot be used as the risk of osteosarcoma is increased in these women. Novel anabolic agents, such as dickkopf- 1 and sclerostin inhibitors, have predominantly been studied in multiple myeloma and cancer metastasis (Lovato \& Lewiecki 2017). Their utility and safety in women treated with endocrine therapy has not been evaluated.

\section{Conclusion}

The longevity of women with ER early positive breast cancer emphasises the importance of mitigating long-term adverse treatment effects on skeletal health. The majority of studies that have evaluated the effects of endocrine therapy on bone health in women with early breast cancer are short-term, most 3 years or less, and based largely on BMD data. Consequently, for premenopausal women in particular, long-term treatment effects on bone quality and fracture risk remain unknown. The effect of treatment cessation on skeletal health is another area that warrants further study. BMD assessment by DXA also has limitations. BMD changes cannot capture the changes in microstructure that occur with endocrine therapy or identify changes in bone volume and matrix mineralisation as two separate entities. Accurate evaluation of these properties is important because they have different effects on bone quality and fracture risk.

There is also a paucity of data to make firm recommendations regarding appropriate fracture risk assessment and ongoing surveillance of bone health in women receiving endocrine therapy. It is increasingly accepted that standard fracture risk assessment tools underestimate fracture risk in women receiving 
endocrine therapy. Moreover, the clinical utility of bone remodelling markers or alternative imaging techniques such as HR-pQCT, in fracture risk assessment and in monitoring treatment response requires further study.

The threshold at which to start bone modifying therapy is also unclear. Whilst most expert societies have suggested a lower treatment threshold in women treated with endocrine therapy (BMD T-score $<-2.0$, fragility fracture or the presence of multiple clinical risk factors for secondary osteoporosis) compared to conventional osteoporosis treatment thresholds (BMD T-score $<-2.5$ or fragility fracture), recent evidence, albeit from a single RCT (Gnant et al. 2015) has suggested anti-fracture benefit with antiresorptive therapy in postmenopausal women with a normal BMD T-score (>-1.0). The effect of applying these same thresholds to premenopausal women has not been studied. Finally, the optimal choice of antiresorptive agent, dosing schedule and treatment duration also remain unanswered questions that warrant further study.

Overall, the effect of severe oestradiol depletion on the skeleton is an important clinical consideration that is best managed with a multidisciplinary model of care. Further research in this area should provide information necessary to formulate evidence-based treatment approaches that improve health outcomes in breast cancer survivors.

\section{Declaration of interest}

Sabashini Ramchand has received speaker honoraria from Counterpart (breast cancer). Mathis Grossmann has received speaker honoraria and conference support from Besins and Amgen Australia, has been an advisory board member for Otsuka and has received research support from Bayer, Novartis, Weight Watchers and Eli Lilly. The other authors have nothing to disclose.

\section{Funding}

This work did not receive any specific grant from any funding agency in the public, commercial or not-for-profit sector.

\section{References}

Akkus O, Polyakova-Akkus A, Adar F \& Schaffler MB 2003 Aging of microstructural compartments in human compact bone. Journal of Bone and Mineral Research 18 1012-1019. (https://doi.org/10.1359/ jbmr.2003.18.6.1012)

Akkus O, Adar F \& Schaffler MB 2004 Age-related changes in physicochemical properties of mineral crystals are related to impaired mechanical function of cortical bone. Bone 34 443-453. (https://doi. org/10.1016/j.bone.2003.11.003)

Albright F, Smith PH \& Richardson AM 1941 Postmenopausal osteoporosis. JAMA 116 2465-2474. (https://doi.org/10.1001/ jama.1941.02820220007002)
Almeida M, Laurent MR, Dubois V, Claessens F, O'brien CA, Bouillon R, Vanderschueren D \& Manolagas SC 2017 Estrogens and androgens in skeletal physiology and pathophysiology. Physiological Reviews $\mathbf{9 7}$ 135-187. (https://doi.org/10.1152/physrev.00033.2015)

Althuis MD, Fergenbaum JH, Garcia-Closas M, Brinton LA, Madigan MP \& Sherman ME 2004 Etiology of hormone receptor-defined breast cancer: a systematic review of the literature. Cancer Epidemiology, Biomarkers and Prevention 13 1558-1568.

Amir E, Seruga B, Niraula S, Carlsson L \& Ocana A 2011 Toxicity of adjuvant endocrine therapy in postmenopausal breast cancer patients: a systematic review and meta-analysis. Journal of the National Cancer Institute 103 1299-1309. (https://doi.org/10.1093/ jnci/djr242)

Bone HG, Bolognese MA, Yuen CK, Kendler DL, Miller PD, Yang YC, Grazette L, San Martin J \& Gallagher JC 2011 Effects of denosumab treatment and discontinuation on bone mineral density and bone turnover markers in postmenopausal women with low bone mass. Journal of Clinical Endocrinology and Metabolism 96 972-980. (https:// doi.org/10.1210/jc.2010-1502)

Boskey AL 2002 Variations in bone mineral properties with age and disease. Journal of Musculoskeletal and Neuronal Interactions 2 532-534.

Bouvard B, Hoppe E, Soulie P, Georgin-Mege M, Jadaud E, AbadieLacourtoisie S, Petit Le Manac'h A, Laffitte A, Levasseur R, Audran M, et al. 2012 High prevalence of vertebral fractures in women with breast cancer starting aromatase inhibitor therapy. Annals of Oncology 23 1151-1156. (https://doi.org/10.1093/annonc/mdr356)

Brufsky A, Harker WG, Beck JT, Carroll R, Tan-Chiu E, Seidler C, Hohneker J, Lacerna L, Petrone S \& Perez EA 2007 Zoledronic acid inhibits adjuvant letrozole-induced bone loss in postmenopausal women with early breast cancer. Journal of Clinical Oncology $\mathbf{2 5}$ 829-836. (https://doi.org/10.1200/JCO.2005.05.3744)

Bundred NJ, Campbell ID, Davidson N, Deboer RH, Eidtmann H, Monnier A, Neven P, Von Minckwitz G, Miller JC, Schenk NL, et al. 2008 Effective inhibition of aromatase inhibitor-associated bone loss by zoledronic acid in postmenopausal women with early breast cancer receiving adjuvant letrozole: ZO-FAST study results. Cancer 112 1001-1010. (https://doi.org/10.1002/cncr.23259)

Burstein HJ, Temin S, Anderson H, Buchholz TA, Davidson NE, Gelmon KE, Giordano SH, Hudis CA, Rowden D, Solky AJ, et al. 2014 Adjuvant endocrine therapy for women with hormone receptorpositive breast cancer: American Society of Clinical Oncology clinical practice guideline focused update. Journal of Clinical Oncology $\mathbf{3 2}$ 2255-2269. (https://doi.org/10.1200/JCO.2013.54.2258)

Burstein HJ, Lacchetti C, Anderson H, Buchholz TA, Davidson NE, Gelmon KE, Giordano SH, Hudis CA, Solky AJ, Stearns V, et al. 2016 Adjuvant endocrine therapy for women With hormone receptorpositive breast cancer: American Society of Clinical Oncology clinical practice guideline update on ovarian suppression. Journal of Clinical Oncology 34 1689-1701. (https://doi.org/10.1200/JCO.2015.65.9573)

Chukir T, Liu Y \& Farooki A 2018 Antiresorptive agents' bone-protective and adjuvant effects in postmenopausal women with early breast cancer. British Journal of Clinical Pharmacology [epub]. (https://doi. org/10.1111/bcp.13834)

Coleman R, DE Boer R, Eidtmann H, Llombart A, Davidson N, Neven P, Von Minckwitz G, Sleeboom HP, Forbes J, Barrios C, et al. 2013 Zoledronic acid (zoledronate) for postmenopausal women with early breast cancer receiving adjuvant letrozole (ZO-FAST study): final 60-month results. Annals of Oncology 24 398-405. (https://doi. org/10.1093/annonc/mds277)

Coleman R, Body JJ, Aapro M, Hadji P, Herrstedt J \& ESMO Guidelines Working Group 2014 Bone health in cancer patients: ESMO Clinical Practice Guidelines. Annals of Oncology 25 (Supplement 3) iii124iii137. (https://doi.org/10.1093/annonc/mdu103)

Coleman RE, Finkelstein D, Barrios CH, Martin M, Iwata H, Glaspy JA, Zhou Y, Jandial D \& Chan A 2018 Adjuvant denosumab in early breast cancer: first results from the international multicenter 
randomized phase III placebo controlled D-CARE study. Journal of Clinical Oncology 36 501. (https://doi.org/10.1200/JCO.2018.36.15_ suppl.501)

Croucher PI, Mcdonald MM \& Martin TJ 2016 Bone metastasis: the importance of the neighbourhood. Nature Reviews: Cancer 16 373-386. (https://doi.org/10.1038/nrc.2016.44)

Cummings SR, San Martin J, McClung MR, Siris ES, Eastell R, Reid IR, Delmas P, Zoog HB, Austin M, Wang A, et al. 2009 Denosumab for prevention of fractures in postmenopausal women with osteoporosis. New England Journal of Medicine 361 756-765. (https://doi: 10.1056/ NEJMoa0809493)

Cummings SR, Ferrari S, Eastell R, Gilchrist N, Jensen JB, Mcclung M, Roux C, Torring O, Valter I, Wang AT, et al. 2018 Vertebral fractures after discontinuation of denosumab: a post hoc analysis of the randomized placebo-controlled FREEDOM trial and its extension. Journal of Bone and Mineral Research 33 190-198. (https://doi. org/10.1002/jbmr.3337)

Davies C, Pan H, Godwin J, Gray R, Arriagada R, Raina V, Abraham M, Medeiros Alencar VH, Badran A, Bonfill X, et al. 2013 Long-term effects of continuing adjuvant tamoxifen to 10 years versus stopping at 5 years after diagnosis of oestrogen receptor-positive breast cancer: ATLAS, a randomised trial. Lancet 381 805-816. (https://doi. org/10.1016/S0140-6736(12)61963-1)

Davies C, Pan H \& Peto R 201710 vs 5 years of adjuvant tamoxifen: exclusion of 1/402 centres in ATLAS. Lancet 389 1884. (https://doi. org/10.1016/S0140-6736(17)31003-6)

Dhesy-Thind S, Fletcher GG, Blanchette PS, Clemons MJ, Dillmon MS, Frank ES, Gandhi S, Gupta R, Mates M, Moy B, et al. 2017 Use of adjuvant bisphosphonates and other bone-modifying agents in breast cancer: a cancer care Ontario and American Society of Clinical Oncology clinical practice guideline. Journal of Clinical Oncology 35 2062-2081. (https://doi.org/10.1200/JCO.2016.70.7257)

Early Breast Cancer Trialists' Collaborative Group (EBCTCG) 2015a Adjuvant bisphosphonate treatment in early breast cancer: metaanalyses of individual patient data from randomised trials. Lancet $\mathbf{3 8 6}$ 1353-1361.

Early Breast Cancer Trialists' Collaborative Group (EBCTCG) $2015 b$ Aromatase inhibitors versus tamoxifen in early breast cancer: patientlevel meta-analysis of the randomised trials. Lancet 386 1341-1352. (https://doi.org/10.1016/S0140-6736(15)61074-1)

Early Breast Cancer Trialists' Collaborative Group (EBCTCG), Davies C, Godwin J, Gray R, Clarke M, Cutter D, Darby S, McGale P, Pan HC, Taylor C, et al. 2011 Relevance of breast cancer hormone receptors and other factors to the efficacy of adjuvant tamoxifen: patient-level meta-analysis of randomised trials. Lancet 378 771-784. (https://doi. org/10.1016/S0140-6736(11)60993-8)

Eidtmann H, DE Boer R, Bundred N, Llombart-Cussac A, Davidson N, Neven P, Von Minckwitz G, Miller J, Schenk N \& Coleman R 2010 Efficacy of zoledronic acid in postmenopausal women with early breast cancer receiving adjuvant letrozole: 36-month results of the ZO-FAST study. Annals of Oncology 21 2188-2194. (https://doi. org/10.1093/annonc/mdq217)

Eriksen EF 1986 Normal and pathological remodeling of human trabecular bone: three dimensional reconstruction of the remodeling sequence in normals and in metabolic bone disease. Endocrine Reviews 7 379-408. (https://doi.org/10.1210/edrv-7-4-379)

Eriksen EF, Gundersen HJ, Melsen F \& Mosekilde L 1984a Reconstruction of the formative site in iliac trabecular bone in 20 normal individuals employing a kinetic model for matrix and mineral apposition. Metabolic Bone Disease and Related Research 5 243-252. (https://doi. org/10.1016/0221-8747(84)90066-3)

Eriksen EF, Melsen F \& Mosekilde L 1984b Reconstruction of the resorptive site in iliac trabecular bone: a kinetic model for bone resorption in 20 normal individuals. Metabolic Bone Disease and Related Research 5 235-242. (https://doi.org/10.1016/02218747(84)90065-1)
Evans CT, Ledesma DB, Schulz TZ, Simpson ER \& Mendelson CR 1986 Isolation and characterization of a complementary DNA specific for human aromatase-system cytochrome P-450 mRNA. PNAS 83 6387-6391. (https://doi.org/10.1073/pnas.83.17.6387)

Fisher B, Costantino JP, Wickerham DL, Cecchini RS, Cronin WM, Robidoux A, Bevers TB, Kavanah MT, Atkins JN, Margolese RG, et al. 2005 Tamoxifen for the prevention of breast cancer: current status of the National Surgical Adjuvant Breast and Bowel Project P-1 study. Journal of the National Cancer Institute 97 1652-1662. (https://doi. org/10.1093/jnci/dji372)

Fogelman I, Blake GM, Blamey R, Palmer M, Sauerbrei W, Schumacher M, Serin D, Stewart A \& Wilpshaar W 2003 Bone mineral density in premenopausal women treated for node-positive early breast cancer with 2 years of goserelin or 6 months of cyclophosphamide, methotrexate and 5-fluorouracil (CMF). Osteoporosis International 14 1001-1006. (https://doi.org/10.1007/s00198-003-1508-y)

Francis PA, Pagani O, Fleming GF, Walley BA, Colleoni M, Lang I, Gomez HL, Tondini C, Ciruelos E, Burstein HJ, et al. 2018 Tailoring adjuvant endocrine therapy for premenopausal breast cancer. New England Journal of Medicine 379 122-137. (https://doi.org/10.1056/ NEJMoa1803164)

Frost HM 1964 Dynamics of bone remodeling. In Bone Biodynamics. Ed HM Frost. Boston, MA, USA: Little, Brown \& Co.

Geisler J, King N, Dowsett M, Ottestad L, Lundgren S, Walton P, Kormeset PO \& Lonning PE 1996 Influence of anastrozole (Arimidex), a selective, non-steroidal aromatase inhibitor, on in vivo aromatisation and plasma oestrogen levels in postmenopausal women with breast cancer. British Journal of Cancer $\mathbf{7 4} 1286-1291$. (https:// doi.org/10.1038/bjc.1996.531)

Geisler J, Lonning PE, Krag LE, Lokkevik E, Risberg T, Hagen AI, Schlichting E, Lien EA, Ofjord ES, Eide GE, et al. 2006 Changes in bone and lipid metabolism in postmenopausal women with early breast cancer after terminating 2-year treatment with exemestane: a randomised, placebo-controlled study. European Journal of Cancer $\mathbf{4 2}$ 2968-2975. (https://doi.org/10.1016/j.ejca.2006.07.005)

Gnant M, Mlineritsch B, Luschin-Ebengreuth G, Kainberger F, Kassmann H, Piswanger-Solkner JC, Seifert M, Ploner F, Menzel C, Dubsky P, et al. 2008 Adjuvant endocrine therapy plus zoledronic acid in premenopausal women with early-stage breast cancer: 5-year follow-up of the ABCSG-12 bone-mineral density substudy. Lancet: Oncology 9 840-849. (https://doi.org/10.1016/S1470-2045(08)70204-3)

Gnant M, Pfeiler G, Dubsky PC, Hubalek M, Greil R, Jakesz R, Wette V, Balic M, Haslbauer F, Melbinger E, et al. 2015 Adjuvant denosumab in breast cancer (ABCSG-18): a multicentre, randomised, doubleblind, placebo-controlled trial. Lancet 386 433-443. (https://doi. org/10.1016/S0140-6736(15)60995-3)

Goldvaser H, Barnes TA, Seruga B, Cescon DW, Ocana A, Ribnikar D \& Amir E 2018 Toxicity of extended adjuvant therapy with aromatase inhibitors in early breast cancer: a systematic review and metaanalysis. Journal of the National Cancer Institute 110 31-39. (https:// doi.org/10.1093/jnci/djx141)

Goss PE, QI S, Cheung AM, HU H, Mendes M \& Pritzker KP 2004 Effects of the steroidal aromatase inhibitor exemestane and the nonsteroidal aromatase inhibitor letrozole on bone and lipid metabolism in ovariectomized rats. Clinical Cancer Research 10 5717-5723. (https:// doi.org/10.1158/1078-0432.CCR-04-0438)

Goss PE, Hershman DL, Cheung AM, Ingle JN, Khosla S, Stearns V, Chalchal H, Rowland K, Muss HB, Linden HM, et al. 2014 Effects of adjuvant exemestane versus anastrozole on bone mineral density for women with early breast cancer (MA.27B): a companion analysis of a randomised controlled trial. Lancet: Oncology 15 474-482. (https:// doi.org/10.1016/S1470-2045(14)70035-X)

Goss PE, Ingle JN, Pritchard KI, Robert NJ, Muss H, Gralow J, Gelmon K, Whelan T, Strasser-Weippl K, Rubin S, et al. 2016 Extending aromatase-inhibitor adjuvant therapy to 10 years. New England Journal of Medicine 375 209-219. (https://doi.org/10.1056/NEJMoa1604700) https://joe.bioscientifica.com https://doi.org/10.1530/JOE-19-0077 (c) 2019 Society for Endocrinology Published by Bioscientifica Ltd. Printed in Great Britain 
Gralow JR, Biermann JS, Farooki A, Fornier MN, Gagel RF, Kumar R, Litsas G, Mckay R, Podoloff DA, Srinivas S, et al. 2013 NCCN Task Force Report: bone health in cancer care. Journal of the National Comprehensive Cancer Network 11 (Supplement 3) S1-S50; quiz S51.

Gray RG, Rea D, Handley K, Bowden SJ, Perry P, Earl HM, Poole CJ, Bates T, Chetiyawardana S, Dewar JA, et al. 2013 aTTom: longterm effects of continuing adjuvant tamoxifen to 10 years versus stopping at 5 years in 6,953 women with early breast cancer. Journal of Clinical Oncology 31 abstract 5. (https://doi.org/10.1200/ jco.2013.31.18_suppl.5)

Grossmann M, Ramchand SK, Milat F, Vincent A, Lim E, Kotowicz MA, Hicks J \& Teede H 2018 Assessment and management of bone health in women with oestrogen receptor-positive breast cancer receiving endocrine therapy: position statement of the Endocrine Society of Australia, the Australian and New Zealand Bone and Mineral Society, the Australasian Menopause Society and the Clinical Oncology Society of Australia. Clinical Endocrinology 89 280-296. (https://doi. org/10.1111/cen.13735)

Hadji P, Coleman RE, Wilson C, Powles TJ, Clezardin P, Aapro M, Costa L, Body JJ, Markopoulos C, Santini D, et al. 2016 Adjuvant bisphosphonates in early breast cancer: consensus guidance for clinical practice from a European panel. Annals of Oncology 27 379-390. (https://doi.org/10.1093/annonc/mdv617)

Hadji P, Aapro MS, Body JJ, Gnant M, Brandi ML, Reginster JY, Zillikens MC, Gluer CC, DE Villiers T, Baber R, et al. 2017 Management of aromatase inhibitor-associated bone loss (AIBL) in postmenopausal women with hormone sensitive breast cancer: joint position statement of the IOF, CABS, ECTS, IEG, ESCEO IMS, and SIOG. Journal of Bone Oncology 7 1-12. (https://doi.org/10.1016/j. jbo.2017.03.001)

Hernandez CJ, Gupta A \& Keaveny TM 2006 A biomechanical analysis of the effects of resorption cavities on cancellous bone strength. Journal of Bone and Mineral Research 21 1248-1255. (https://doi.org/10.1359/ jbmr.060514)

Hines SL, Mincey B, Dentchev T, Sloan JA, Perez EA, Johnson DB, Schaefer PL, Alberts S, Liu H, Kahanic S, et al. 2009 Immediate versus delayed zoledronic acid for prevention of bone loss in postmenopausal women with breast cancer starting letrozole after tamoxifen-N03CC. Breast Cancer Research and Treatment 117 603-609. (https://doi.org/10.1007/s10549-009-0332-2)

Juozaityte E, Aleknavicius E, Janciauskiene R, Cesas A, PipirieneZelviene T, Liutkauskiene S, Krasauskiene A \& Venceviciene L 2014 Guidelines for diagnostics and treatment of aromatase inhibitor-induced bone loss in women with breast cancer: a consensus of Lithuanian medical oncologists, radiation oncologists, endocrinologists, and family medicine physicians. Medicina 50 197-203. (https://doi.org/10.1016/j.medici.2014.09.004)

Khosla S \& Monroe DG 2018 Regulation of bone metabolism by sex steroids. Cold Spring Harbor Perspectives in Medicine 8 a031211. (https:// doi.org/10.1101/cshperspect.a031211)

Labrie F, Belanger A, Cusan L \& Candas B 1997 Physiological changes in dehydroepiandrosterone are not reflected by serum levels of active androgens and estrogens but of their metabolites: intracrinology. Journal of Clinical Endocrinology and Metabolism 82 2403-2409. (https://doi.org/10.1210/jcem.82.8.4161)

Labrie F, Belanger A, Luu-The V, Labrie C, Simard J, Cusan L, Gomez JL \& Candas B 1998 DHEA and the intracrine formation of androgens and estrogens in peripheral target tissues: its role during aging. Steroids $\mathbf{6 3}$ 322-328. (https://doi.org/10.1016/S0039-128X(98)00007-5)

Lips P, Courpron P \& Meunier PJ 1978 Mean wall thickness of trabecular bone packets in the human iliac crest: changes with age. Calcified Tissue Research 26 13-17. (https://doi.org/10.1007/BF02013227)

Llombart A, Frassoldati A, Paija O, Sleeboom HP, Jerusalem G, Mebis J, Deleu I, Miller J, Schenk N \& Neven P 2012 Immediate administration of zoledronic acid reduces aromatase inhibitor-associated bone loss in postmenopausal women with early breast cancer: 12 -month analysis of the E-ZO-FAST trial. Clinical Breast Cancer 12 40-48. (https://doi. org/10.1016/j.clbc.2011.08.002)

Lovato C \& Lewiecki EM 2017 Emerging anabolic agents in the treatment of osteoporosis. Expert Opinion on Emerging Drugs 22 247-257. (https://doi.org/10.1080/14728214.2017.1362389)

Love RR, Mazess RB, Barden HS, Epstein S, Newcomb PA, Jordan VC, Carbone PP \& Demets DL 1992 Effects of tamoxifen on bone mineral density in postmenopausal women with breast cancer. New England Journal of Medicine 326 852-856. (https://doi.org/10.1056/ NEJM199203263261302)

Lyles KW, Colon-Emeric CS, Magaziner JS, Adachi JD, Pieper CF, Mautalen C, Hyldstrup L, Recknor C, Nordsletten L, Moore KA, et al. 2007 Zoledronic acid and clinical fractures and mortality after hip fracture. New England Journal of Medicine 357 1799-1809. (https://doi. org/10.1056/NEJMoa074941)

Mamounas EP, Bandos H, Lembersky BC, Jeong JH, Geyer CE, Rastogi P, Fehrenbacher L, Graham ML, Chia SK, Brufsky AM, et al. 2019 Use of letrozole after aromatase inhibitor-based therapy in postmenopausal breast cancer (NRG Oncology/NSABP B-42): a randomised, doubleblind, placebo-controlled, phase 3 trial. Lancet: Oncology 20 88-99. (https://doi.org/10.1016/S1470-2045(18)30621-1)

Maximov PY, Lee TM \& Jordan VC 2013 The discovery and development of selective estrogen receptor modulators (SERMs) for clinical practice. Current Clinical Pharmacology 8 135-155. (https://doi.org/10.2174/157 4884711308020006)

Miller PD, Wagman RB, Peacock M, Lewiecki EM, Bolognese MA, Weinstein RL, Ding B, San Martin J \& McClung MR 2011 Effect of denosumab on bone mineral density and biochemical markers of bone turnover: six-year results of a phase 2 clinical trial. Journal of Clinical Endocrinology and Metabolism 96 394-402. (https://doi. org/10.1210/jc.2010-1805)

Nadji M, Gomez-Fernandez C, Ganjei-Azar P \& Morales AR 2005 Immunohistochemistry of estrogen and progesterone receptors reconsidered: experience with 5,993 breast cancers. American Journal of Clinical Pathology 123 21-27. (https://doi.org/10.1309/4WV79N2G HJ3X1841)

Nourmoussavi M, Pansegrau G, Popesku J, Hammond GL, Kwon JS \& Carey MS 2017 Ovarian ablation for premenopausal breast cancer: a review of treatment considerations and the impact of premature menopause. Cancer Treatment Reviews 55 26-35. (https://doi. org/10.1016/j.ctrv.2017.02.005)

Pagani O, Regan MM, Walley BA, Fleming GF, Colleoni M, Lang I, Gomez HL, Tondini C, Burstein HJ, Perez EA, et al. 2014 Adjuvant exemestane with ovarian suppression in premenopausal breast cancer. New England Journal of Medicine 371 107-118. (https://doi. org/10.1056/NEJMoa1404037)

Paterson AH \& Shea-Budgell MA 2013 Bone health in patients with breast cancer: recommendations from an evidence-based Canadian guideline. Journal of Clinical Medicine 2 283-301. (https://doi. org/10.3390/jcm2040283)

Pedersini R, Monteverdi S, Mazziotti G, Amoroso V, Roca E, Maffezzoni F, Vassalli L, Rodella F, Formenti AM, Frara S, et al. 2017 Morphometric vertebral fractures in breast cancer patients treated with adjuvant aromatase inhibitor therapy: a cross-sectional study. Bone 97 147-152. (https://doi.org/10.1016/j.bone.2017.01.013)

Pisani P, Renna MD, Conversano F, Casciaro E, DI Paola M, Quarta E, Muratore M \& Casciaro S 2016 Major osteoporotic fragility fractures: risk factor updates and societal impact. World Journal of Orthopedics 7 171-181. (https://doi.org/10.5312/wjo.v7.i3.171)

Powles TJ, Hickish T, Kanis JA, Tidy A \& Ashley S 1996 Effect of tamoxifen on bone mineral density measured by dual-energy X-ray absorptiometry in healthy premenopausal and postmenopausal women. Journal of Clinical Oncology 14 78-84. (https://doi. org/10.1200/JCO.1996.14.1.78)

Ramchand SK, Seeman E, Wang XF, Ghasem-Zadeh A, Francis PA, Ponnusamy EJ, Bardin MS, Bui M, Zebaze R, Zajac JD, et al. 2017 https://joe.bioscientifica.com

https://doi.org/10.1530/JOE-19-0077
(C) 2019 Society for Endocrinology Published by Bioscientifica Ltd.
Printed in Great Britain 
Premenopausal women with early breast cancer treated with estradiol suppression have severely deteriorated bone microstructure. Bone 103 131-135. (https://doi.org/10.1016/j.bone.2017.06.024)

Regan MM, Pagani O, Fleming GF, Walley BA, Price KN, Rabaglio M, Maibach R, Ruepp B, Coates AS, Goldhirsch A, et al. 2013 Adjuvant treatment of premenopausal women with endocrine-responsive early breast cancer: design of the TEXT and SOFT trials. Breast $\mathbf{2 2}$ 1094-1100. (https://doi.org/10.1016/j.breast.2013.08.009)

Riggs BL, Khosla S \& Melton LJ 3rd 2002 Sex steroids and the construction and conservation of the adult skeleton. Endocrine Reviews 23 279-302. (https://doi.org/10.1210/edrv.23.3.0465)

Schaffler MB \& Burr DB 1988 Stiffness of compact bone: effects of porosity and density. Journal of Biomechanics 21 13-16. (https://doi. org/10.1016/0021-9290(88)90186-8)

Seeman E 2010 Bone morphology in response to alendronate as seen by high-resolution computed tomography: through a glass darkly. Journal of Bone and Mineral Research 25 2553-2557. (https://doi. org/10.1002/jbmr.261)

Silva TC, Barrett-Connor E, Ramires JA \& Mansur AP 2008 Obesity, estrone, and coronary artery disease in postmenopausal women. Maturitas 59 242-248. (https://doi.org/10.1016/j. maturitas.2008.01.008)

Simpson E \& Santen RJ 2015 Celebrating 75 years of oestradiol. Journal of Molecular Endocrinology 55 T1-T20. (https://doi.org/10.1530/JME-150128)

Simpson E, Rubin G, Clyne C, Robertson K, O’Donnell L, Jones M \& Davis S 2000 The role of local estrogen biosynthesis in males and females. Trends in Endocrinology and Metabolism 11 184-188. (https:// doi.org/10.1016/S1043-2760(00)00254-X)

Singapore Cancer Network Breast Cancer Workgroup 2015 Singapore Cancer Network (SCAN) guidelines for bisphosphonate use in the adjuvant breast cancer setting. Annals of the Academy of Medicine $\mathbf{4 4}$ 368-378.

Smith I, Yardley D, Burris H, De Boer R, Amadori D, Mcintyre K, Ejlertsen B, Gnant M, Jonat W, Pritchard KI, et al. 2017 Comparative efficacy and safety of adjuvant letrozole versus anastrozole in postmenopausal patients with hormone receptor-positive, node- positive early breast cancer: final results of the randomized phase III femara versus anastrozole clinical evaluation (FACE) trial. Journal of Clinical Oncology 35 1041-1048. (https://doi.org/10.1200/ JCO.2016.69.2871)

Sverrisdottir A, Fornander T, Jacobsson H, Von Schoultz E \& Rutqvist LE 2004 Bone mineral density among premenopausal women with early breast cancer in a randomized trial of adjuvant endocrine therapy. Journal of Clinical Oncology 22 3694-3699. (https://doi.org/10.1200/ JCO.2004.08.148)

Tjan-Heijnen VCG, Van Hellemond IEG, Peer PGM, Swinkels ACP, Smorenburg CH, Van Der Sangen MJC, Kroep JR, DE Graaf H, Honkoop AH, Erdkamp FLG, et al. 2017 Extended adjuvant aromatase inhibition after sequential endocrine therapy (DATA): a randomised, phase 3 trial. Lancet: Oncology 18 1502-1511. (https:// doi.org/10.1016/S1470-2045(17)30600-9)

Tran Van P, Vignery A \& Baron R 1982 An electron-microscopic study of the bone-remodeling sequence in the rat. Cell and Tissue Research 225 283-292. (https://doi.org/10.1007/BF00214682)

Tremollieres FA, Ceausu I, Depypere H, Lambrinoudaki I, Mueck A, Perez-Lopez FR, Van Der Schouw YT, Senturk LM, Simoncini T, Stevenson JC, et al. 2017 Osteoporosis management in patients with breast cancer: EMAS position statement. Maturitas 95 65-71. (https:// doi.org/10.1016/j.maturitas.2016.10.007)

Tseng OL, Spinelli JJ, Gotay CC, HO WY, Mcbride ML \& Dawes MG 2018 Aromatase inhibitors are associated with a higher fracture risk than tamoxifen: a systematic review and meta-analysis. Therapeutic Advances in Musculoskeletal Disease 10 71-90. (https://doi.org/10.1177 /1759720X18759291)

Tsourdi E, Langdahl B, Cohen-Solal M, Aubry-Rozier B, Eriksen EF, Guanabens N, Obermayer-Pietsch B, Ralston SH, Eastell R \& Zillikens MC 2017 Discontinuation of denosumab therapy for osteoporosis: a systematic review and position statement by ECTS. Bone 105 11-17. (https://doi.org/10.1016/j.bone.2017.08.003)

Vedi S, Compston JE, Webb A \& Tighe JR 1983-1984 Histomorphometric analysis of dynamic parameters of trabecular bone formation in the iliac crest of normal British subjects. Metabolic Bone Disease and Related Research 5 69-74. (https://doi.org/10.1016/0221-8747(83)90004-8)

Received in final form 3 April 2019

Accepted 15 April 2019

Accepted Preprint published online 16 April 2019 (c) 2019 Society for Endocrinology Published by Bioscientifica Ltd.
Printed in Great Britain 